\title{
FUNCIONALIDADE DE ALUNOS COM DEFICIÊNCIA FÍSICA NAS ATIVIDADES DE ESCRITA E DE USO DO COMPUTADOR
}

\author{
FUNCIONALIDAD DE ALUMNOS CON DISCAPACIDAD EN LAS \\ ACTIVIDADES DE ESCRITURA Y DE USO DEL COMPUTADOR
}

\section{FUNCTIONALITY OF STUDENTS WITH PHYSICAL DEFICIENCY IN WRITING AND COMPUTER USE ACTIVITIES}

\author{
Fernanda Matrigani Mercado GUTIERRES DE QUEIROZ ${ }^{1}$ \\ Lígia Maria Presumido BRACCIALLI ${ }^{2}$
}

RESUMO: A inclusão educacional se preocupa com a aprendizagem de todos os alunos que enfrentam barreiras para participar efetivamente da vida escolar. $\mathrm{Na}$ perspectiva da educação inclusiva, o aluno com deficiência deve ser atendido preferencialmente no ensino comum, e a educação especial oferece o Atendimento Educacional Especializado para complementar suas necessidades educacionais. Neste contexto, revela-se o objetivo desta pesquisa: Descrever a funcionalidade de alunos com deficiência física, de Salas de Recursos Multifuncionais, para as atividades de escrita e de uso de computador, segundo a percepção dos professores. Participaram do estudo os professores do Atendimento Educacional Especializado que atendem alunos com deficiência física. Para coleta dos dados foi utilizado o instrumento padronizado School Function Assessment. Os dados foram organizados em um documento único, sendo apresentadas as categorias 1) Trabalho escrito; 2) Uso do computador e equipamentos. Concluiu-se que os estudantes com deficiência física, principalmente os que apresentam a funcionalidade dos membros superiores prejudicada podem sentir dificuldades para escrever utilizando os materiais convencionais, para tanto necessitam da Tecnologia Assistiva para desenvolver suas habilidades de escrita. Portanto, mostra-se importante aprimorar o levantamento do perfil funcional do aluno para escolha do recurso, bem como faz-se necessário aprimorar os materiais das Salas de Recursos Multifuncionais para atenderem a diversidade de todos os alunos com deficiência física, pois o tipo de mobiliário, materiais didático-pedagógicos e equipamentos, não favorecem seu uso pelos alunos com sérios comprometimentos motores.

PALAVRAS-CHAVE: Educação especial. Tecnologia assistiva. Deficiência física. Escrita.

RESUMEN: La inclusión educativa se preocupa con el aprendizaje de todos los alumnos que enfrentan barreras para participar efectivamente en la vida escolar. En la perspectiva de la educación inclusiva, el alumno discapacitado debe ser atendido

\footnotetext{
${ }^{1}$ Faculdade de Educação da Universidade Federal da Bahia (UFBA), Bahia - Brasil. Professora do Departamento de Educação I. Doutoranda em Psicologia Escolar e do Desenvolvimento Humano pela Universidade de São Paulo (USP). E-mail: fernanda.queiroz@ufba.br.

${ }^{2}$ Universidade Estadual Paulista (UNESP), Marília - SP - Brasil. Docente do Departamento de Educação Especial e do Programa de Pós-Graduação em Educação da FFC. E-mail: bracci@marilia.unesp.br.
} 
preferencialmente en la educación regular y la educación especial ofrece la Atención Educativa Especializada para complementar sus necesidades educativas. En este contexto, se revela el objetivo de este estudio: Describir la funcionalidad de alumnos con discapacidad, de Aulas de Recursos Multifuncionales, para las actividades de escritura y de uso de computador, según la percepción de los profesores. Participaron del estudio los profesores de la Atención Educativa Especializada que atienden alumnos con discapacidad. Para colectar los datos fue utilizado el instrumento standard School Function Assessment. Los datos fueron organizados en un documento único, siendo presentadas las categorías 1) Trabajo escrito; 2) Uso del computador y equipos. Se concluyó que los estudiantes con discapacidad, principalmente los que presentan la funcionalidad de los miembros superiores perjudicada, pueden sentir dificultades para escribir utilizando los materiales convencionales, para tanto necesitan Tecnología Asistiva para que desarrollen sus habilidades de escritura. Por lo tanto, se muestra importante mejorar la recopilación del perfil funcional del alumno para escoger el recurso, bien como se hace necesario mejorar los materiales de las Aulas de Recursos Multifuncionales para que atiendan la diversidad de todos los alumnos con discapacidad, pues el tipo de mobiliario, materiales didácticopedagógicos y equipos, no favorecen su uso por los alunos con serios impedimentos motores.

PALABRAS CLAVE: Educación especial. Tecnología asistiva. Discapacidad. Escritura.

ABSTRACT: The educational inclusion is focused on the learning of all students that have confronts barriers in to effective participation in the school life. In the inclusive education perspective, the students with disabilities must meet be served preferably in the regular education and the special education that needs to offer the educational attendance specialized to complement their educational needs. In this context, the objective of the research is defined in: Describe the functionality of students with physical disabilities, in the Multifunctional Resource Rooms, for activities of writing and computer use, according to the perception of the teachers. The participants of this analysis were teachers of the Educational Service Specialist that are serving students with disabilities. For data collection was used instrument School Function Assessment. The data were organized into a single document, the categories being presented. 1)Written work; 2)Use of the computer and the equipment. The conclusion was that students with physical disabilities, especially those with impaired upper-limb functionality can have find difficult to write using conventional materials, so they need Assistive Technology to develop their writing skills. Therefore, it is important to improve the profile analysis of the student, thus to choose the more appropriate resource as, it is necessary to improve the materials of the Multifunctional Resource Rooms to meet the diversity of all students with physical disabilities, since the type of furniture, didactic-pedagogical materials and equipment, are not favor in the use by students with serious motor disabilities.

KEYWORDS: Special education. Assistive technology. Physical disabilities. Writing. 


\section{Introdução}

A educação inclusiva é um processo educacional que se estrutura em função das necessidades dos alunos e se preocupa com a aprendizagem de todos (STAINBACK; STAINBACK, 1999). Assim, é necessário que se tenha condições pedagógicas e tecnológicas para a aprendizagem do aluno.

Para a construção do conhecimento, o ser humano necessita da mediação social. Como afirma Vygotsky $(1997$; 2003) o que decide o destino da pessoa não é a deficiência em si, senão suas consequências sociais. De acordo com o estímulo social, pode-se impulsionar a busca de rotas alternativas de desenvolvimento em um movimento compensatório, e os instrumentos de mediação atuam na relação do homem com o mundo como objetos carregados de significados culturais.

Para a melhoria da qualidade de vida das pessoas com deficiência tem especial relevância a Tecnologia Assistiva (BRACCIALLI, 2007; BRACCIALLI; REBELO; PEREIRA, 2012), porém as dificuldades de participação experimentadas por algumas crianças com deficiência podem ser agravadas quando há falta de estímulos e preconceitos do meio, podendo gerar uma tendência à passividade (COSTER et al., 2013; QUEIROZ; BRACCIALLI, 2013).

Para optar pelo recurso adequado no atendimento ao aluno com deficiência física (DF), pois este aluno apresenta características variadas e comprometimentos em diversos níveis, cabe ao professor do Atendimento Educacional Especializado (AEE), não somente dominar o uso dos diferentes dispositivos disponibilizados nas Salas de Recursos, como também conhecer o perfil funcional dos alunos para poder prescrevêlos e/ou confeccioná-los dependendo do caso.

Na perspectiva da Classificação Internacional de Funcionalidade, Incapacidade e Saúde - CIF (OMS, 2004) funcionalidade é um termo que engloba todas as funções do corpo, atividades e participação. A CIF tem como perspectiva de percepção da funcionalidade e capacidade da pessoa ao invés do foco na doença e incapacidade ou deficiência. Portanto, em um modelo inclusivo, ao valorizar as habilidades individuais para prescrição de Tecnologia Assistiva (TA), busca-se a conquista de novas competências e de autonomia. Neste contexto a deficiência de movimento é uma característica individual, portanto o professor deve saber observar a funcionalidade do aluno para atuar pedagogicamente, e assim poder aproveitar ao máximo seu potencial na construção do conhecimento. 
Abe (2009) investigou a participação escolar de alunos com necessidades especiais por meio da SFA, identificando os níveis de auxílio oferecidos às crianças. Os resultados indicaram boa participação, mas elevados níveis de assistência de terceiros. Considera-se a indicação de adaptações para diminuir a necessidade de auxílio.

Em seu estudo com professores da Educação Infantil, Bagagi (2010) utilizou a SFA para mensurar a participação, níveis de auxílio de desempenho de atividades funcionais de alunos com deficiências na escola. Os resultados apontaram que estas crianças avaliadas por seus professores não apresentavam elevadas dificuldades para desempenhar atividades de rotina escolar.

Em sua pesquisa sobre a independência funcional, motricidade e participação escolar e suas relações no desenvolvimento da criança com paralisia cerebral, Rézio (2012) analisou a associação entre o nível de independência funcional, a motricidade e a participação de crianças com paralisia cerebral. Na avaliação utilizou os instrumentos padronizados, Gross Motor Function Classification System (GMFCS), Ficha de avaliação neurológica, Avaliação socioeconômica, Pediatric Evalution of Disability Inventory (PEDI), Gross Motor Function Measure (GMFM) e School Function Assessement (SFA). Os resultados mostraram que as crianças que apresentam um maior nível de independência funcional e um melhor desempenho na função motora recebem menos adaptações e assistência nas suas atividades escolares. Por sua vez, crianças mais dependentes na funcionalidade e na motricidade grossa apresentam mais dificuldades nas relações sociais e adaptação escolar (RÉZIO, 2012).

Assim, torna-se importante descrever a funcionalidade de alunos com deficiência física, das Salas de Recursos Multifuncionais, para as atividades de escrita e de uso do computador, segundo a percepção dos professores.

\section{Método}

\section{Procedimentos éticos}

O projeto de pesquisa foi submetido ao Comitê de Ética em Pesquisa da Faculdade de Filosofia e Ciências, aprovado com o parecer número 0664/2013. Na sequência foram obtidas as devidas autorizações e os participantes do estudo assinaram o Termo de Consentimento Livre e Esclarecido.

\section{Caracterização dos participantes}


Participaram da pesquisa sete professores, que se configuram como todos os professores do AEE do município que atendiam alunos com DF. Eles atenderam aos seguintes critérios de inclusão: ser professor do AEE na Rede Municipal de Ensino, atender alunos do $1^{\circ}$ ao $5^{\circ}$ ano do Ensino Fundamental com DF e concordar em participar do estudo. No Quadro 1 pode-se visualizar as características das professoras participantes.

Quadro 1: Caracterização dos participantes do estudo.

\begin{tabular}{|c|c|c|c|c|c|}
\hline Participante & Idade & Gênero & Formação inicial & Especialização*** & $\begin{array}{c}\text { Tempo de } \\
\text { Atuação (anos) }\end{array}$ \\
\hline P1 & 39 & $\mathrm{~F}$ & Pedagogia & Deficiência Mental* & 3 \\
\hline $\mathbf{P 2}$ & 25 & $\mathrm{~F}$ & Pedagogia & Deficiência Mental* & 3 \\
\hline P3 & 33 & $\mathrm{~F}$ & $\begin{array}{c}\text { Pedagogia com } \\
\text { Habilitação em } \\
\text { Deficiência Intelectual }\end{array}$ & $\begin{array}{l}\text { Psicopedagogia e } \\
\text { Educação especial }\end{array}$ & 7 \\
\hline P4 & $\begin{array}{l}\text { Não } \\
\text { infor } \\
\text { mado }\end{array}$ & $\mathrm{F}$ & Pedagogia & $\begin{array}{c}\text { Educação inclusiva } \\
\text { especial, } \\
\text { Psicopedagogia e } \\
\text { Deficiência Auditiva. }\end{array}$ & 2 \\
\hline P5 & 36 & $\mathrm{~F}$ & $\begin{array}{c}\text { Pedagogia com } \\
\text { habilitação } \\
\text { administração e } \\
\text { supervisão escolar. } \\
\text { Deficiência mental* }\end{array}$ & Psicopedagogia & 2 \\
\hline P6 & 33 & $\mathrm{~F}$ & $\begin{array}{c}\text { Pedagogia com } \\
\text { habilitação em } \\
\text { Deficiência Intelectual }\end{array}$ & - & 4 \\
\hline P7 & 26 & $\mathrm{~F}$ & $\begin{array}{c}\text { Pedagogia habilitação } \\
\text { em deficiência } \\
\text { mental*. }\end{array}$ & $\begin{array}{c}\text { AEE na área de } \\
\text { Deficiência Intelectual }\end{array}$ & 4 \\
\hline
\end{tabular}

Fonte: Elaboração própria.

*Termo utilizado na época da obtenção da especialização. **Nenhuma possui especialização em Deficiência Física.

As professoras trabalhavam quatro horas diárias no AEE, no período matutino ou vespertino, exceto P3, que trabalhava nos dois períodos na mesma escola. Elas atendiam alunos com deficiência física e intelectual, bem como alunos que apresentavam outras deficiências, como segue: P1, P2, P4 e P7, alunos com surdez e P3, autismo.

\section{Local e período}

A pesquisa foi realizada nas Escolas Municipais de Ensino Fundamental I de uma cidade de médio porte do interior paulista, que funcionavam como escolas Polos do 
Atendimento Educacional Especializado por possuírem Salas de Recursos Multifuncionais (SRM). Os dados foram coletados em todas as Salas de recursos multifuncionais da cidade, que atendiam alunos com DF.

\section{Instrumentos e procedimentos para coleta de dados}

Para a coleta de dados foi utilizado o instrumento padronizado School Function Assessment (SFA). A SFA foi considerada por Silva (2007) "um importante instrumento de avaliação padronizado com ênfase na escola", capaz de identificar a participação e o desempenho escolar de crianças com diferentes incapacidades e níveis de comprometimento motor, seja no ensino comum ou especial.

A escala SFA (COSTER et al., 1998) fornece informações sobre a funcionalidade do aluno no ambiente escolar nas áreas de participação, auxílio no desempenho de tarefas e desempenho de atividades. Consiste em um formulário com três partes distintas. A parte I é a escala de participação, a parte II é formada por duas escalas, uma de tarefas físicas e outra cognitivo/comportamentais, subdivididas quanto à necessidade de assistência e adaptação, e a parte III inclui 12 escalas de desempenho de atividades de tarefas físicas e nove escalas de desempenho em atividades cognitivo/comportamentais. Para os autores da escala, a participação se refere ao envolvimento ativo do aluno em atividades características de um ambiente particular de sua escola, que acontece em um ambiente de atividade que se define como um conjunto de atividades relacionadas, incluindo o contexto físico e social em que elas ocorrem para as crianças da escola (COSTER, et al, 1998).

Pelo exposto por Coster et al. (1998), as tarefas cognitivo/comportamentais são as que dependem mais das habilidades cognitivas, sociais ou comportamentais para o seu desempenho, e as tarefas físicas foram assim designadas por envolverem um componente físico significativo para serem desempenhadas.

A SFA fornece informações sobre as capacidades e limitações funcionais do aluno e capacita o examinador a analisar todas as áreas importantes de função escolar para crianças de educação infantil e ensino fundamental, com atenção nas áreas desafiadoras para alunos com deficiência física ou sensorial.

O modelo conceitual foi embasado na função e segue uma ordem "top-down". Neste contexto a função é reconhecida como uma construção complexa definida em vários níveis, do global ao específico (COSTER, et al.,1998), desde um amplo enfoque 
sobre qualidade de vida até a habilidade de desempenhar uma atividade específica; cada nível da escala enfoca um diferente aspecto da função.

A abordagem "top-down”, segundo Abe (2009), tem como ponto de partida da avaliação a participação ampla para depois examinar os componentes específicos do desempenho, ou seja, parte da investigação da participação do aluno para posteriormente questionar seu desempenho nas atividades.

Para a coleta de dados, um primeiro contato com as professoras do AEE foi realizado em uma reunião na Secretaria Municipal de Educação, com autorização da gestão da área de Educação Especial. Neste encontro foi exposto sobre a pesquisa, verificado quais professoras tinham interesse em participar e questionado quais professoras atendiam, neste ano, alunos com DF. Sete professoras afirmaram atender alunos com DF e todas elas se dispuseram a participar.

Em uma primeira etapa procurou-se identificar o perfil funcional do alunado das salas de recursos, por meio da aplicação do instrumento SFA, que foi respondido pelas professoras das Salas de Recursos Multifuncionais pesquisadas. As professoras responderam as escalas específicas selecionadas da SFA para cada aluno com DF que participava da sala de recursos na qual cada uma era responsável.

Foi realizado contato com um professor participante por vez para agendar a aplicação da SFA. Inicialmente as participantes foram esclarecidas sobre o teor do instrumento e orientadas pela pesquisadora, conforme descrito no manual da SFA; o número de encontros foi variado em função do número de alunos com DF atendidos pelas mesmas. Foram aplicadas 15 escalas SFA com as professoras, sendo uma referente a cada aluno com deficiência física.

Os encontros foram realizados nas próprias escolas nas salas de recursos nos dias e horários de conveniência da participante. Nos encontros era preenchida a SFA sobre cada aluno com DF; como havia professoras que atendiam de um até quatro alunos com DF, a pesquisadora retornou às escolas quantas vezes foram necessárias.

\section{Procedimentos para análise de dados}

Os resultados das escalas aplicadas foram mensurados e transformados de escore bruto em escore padronizado de 0 a 100 pontos para cada escala, de acordo com os critérios determinados nas tabelas do manual da SFA. De acordo com o exposto por Coster et al. (1998), a pesquisadora que for analisar os resultados precisa ter formação 
profissional em Fisioterapia, Terapia ocupacional, Pedagogia, Fonoaudiologia ou Psicologia, além de estar familiarizada com o uso de instrumentos padronizados, estudar o manual da SFA e ter conhecimento sobre as condições do alunado da Educação Especial.

Os dados coletados pela aplicação da SFA foram analisados pela pesquisadora que tem formação em Psicologia e Pedagogia e familiarização com o uso de instrumentos padronizados e experiência na Educação Especial. Os dados foram tabulados por meio do software Microsoft Office Excel 2010 em forma de frequência absoluta. Nesse programa, os dados foram organizados em tabelas e gerados gráficos organizados por escala aplicada e por nível de desempenho dos alunos nas atividades das escalas: Trabalho escrito e Uso do computador e equipamentos.

\section{Resultados}

Os resultados do estudo foram apresentados em relação: a) ao perfil funcional do grupo de alunos com DF acompanhados pelo AEE; b) trabalho escrito; c) uso do computador e equipamentos.

\section{Perfil funcional do grupo de alunos com deficiência física acompanhados pelo} AEE.

Os dados referentes à caracterização dos alunos com DF acompanhados pelo AEE foram expressos no Quadro 2, de acordo com as informações das professoras participantes.

Quadro 2: Caracterização dos alunos quanto a mobilidade, acomodação/posicionamento e comprometimento de movimentos

\begin{tabular}{|c|c|c|c|c|c|c|c|c|c|}
\hline \multirow[t]{2}{*}{$\begin{array}{l}\text { Parti } \\
\text { cipan } \\
\text { tes }\end{array}$} & \multirow[t]{2}{*}{$\begin{array}{c}\text { Alu } \\
\text { no }\end{array}$} & \multirow[t]{2}{*}{$\begin{array}{l}\text { Gê } \\
\text { ne } \\
\text { ro }\end{array}$} & \multirow[t]{2}{*}{$\begin{array}{l}\text { Idade } \\
\text { em } \\
\text { anos }\end{array}$} & \multirow[t]{2}{*}{$\begin{array}{l}\text { Ano } \\
\text { Esco } \\
\text { lar }\end{array}$} & \multirow{2}{*}{$\begin{array}{l}\text { Hipó } \\
\text { tese } \\
\text { Diag } \\
\text { nóstica }\end{array}$} & \multirow[t]{2}{*}{ Mobilidade } & \multirow[t]{2}{*}{$\begin{array}{l}\text { Acomodação/ } \\
\text { Posicionamento }\end{array}$} & \multicolumn{2}{|c|}{$\begin{array}{l}\text { Comprometi } \\
\text { mento do } \\
\text { Movimento }\end{array}$} \\
\hline & & & & & & & & Inf. & Sup \\
\hline P1 & A1 & M & 8 & 3 & Mielo & Cad. Rodas* & $\begin{array}{l}\text { Mesa redonda } \\
\text { Cadeira Rodas }\end{array}$ & $\mathrm{D} / \mathrm{E}$ & $\mathrm{E}$ \\
\hline \multirow[t]{2}{*}{$\mathrm{P} 2$} & A2 & M & 7 & 1 & $\mathrm{PC}$ & Cad. Rodas* & $\begin{array}{l}\text { Mesa redonda } \\
\text { Cadeira Rodas }\end{array}$ & $\mathrm{D} / \mathrm{E}$ & $\mathrm{D} / \mathrm{E}$ \\
\hline & A3 & $\mathrm{F}$ & 6 & 1 & PC & Andar ** & $\begin{array}{c}\text { Mesa redonda } \\
\text { Cadeira estofada }\end{array}$ & D & D \\
\hline
\end{tabular}




\begin{tabular}{|c|c|c|c|c|c|c|c|c|c|}
\hline & A4 & $\mathrm{M}$ & 11 & 5 & $\mathrm{PC}$ & Andar ** & $\begin{array}{c}\text { Mesa redonda } \\
\text { Cadeira estofada }\end{array}$ & $\mathrm{D}$ & $\mathrm{D}$ \\
\hline \multirow[t]{4}{*}{ P3 } & A5 & $\mathrm{F}$ & 8 & 3 & $\mathrm{PC}$ & $\begin{array}{c}\text { Bengala } \\
\text { canadense }\end{array}$ & $\begin{array}{l}\text { Carteira escolar } \\
\text { Cadeira escol. }\end{array}$ & $\mathrm{D} / \mathrm{E}$ & - \\
\hline & A6 & $\mathrm{M}$ & 14 & 5 & PC & Cad. Rodas* & $\begin{array}{c}\text { Outra mesa } \\
\text { Cadeira Rodas }\end{array}$ & $\mathrm{D} / \mathrm{E}$ & $\mathrm{D} / \mathrm{E}$ \\
\hline & A7 & $\mathrm{M}$ & 12 & 5 & Mielo & Cad. Rodas* & $\begin{array}{c}\text { Outra mesa } \\
\text { Cadeira Rodas }\end{array}$ & $\mathrm{D} / \mathrm{E}$ & - \\
\hline & A8 & $\mathrm{M}$ & 9 & 4 & Mielo & Andar ** & $\begin{array}{l}\text { Mesa com recorte } \\
\text { semicírculo } \\
\text { Cadeira escolar }\end{array}$ & $\mathrm{E}$ & - \\
\hline \multirow[t]{2}{*}{$\mathrm{P} 4$} & A9 & $\mathrm{M}$ & 9 & 3 & Mielo & Cad. Rodas* & $\begin{array}{l}\text { Mesa redonda } \\
\text { Cadeira Rodas }\end{array}$ & $\mathrm{D} / \mathrm{E}$ & - \\
\hline & A10 & $\mathrm{M}$ & 7 & 1 & PC & Cad. Rodas* & $\begin{array}{l}\text { Carteira Escolar } \\
\text { Cadeira Rodas }\end{array}$ & $\mathrm{D} / \mathrm{E}$ & $\mathrm{D} / \mathrm{E}$ \\
\hline \multirow[t]{2}{*}{ P5 } & A11 & $\mathrm{M}$ & 7 & 2 & Mielo & Cad. Rodas* & $\begin{array}{l}\text { Carteira Escolar } \\
\text { Cadeira Rodas }\end{array}$ & $\mathrm{D} / \mathrm{E}$ & - \\
\hline & A12 & $\mathrm{M}$ & 7 & 2 & $\mathrm{PC}$ & Cad. Rodas* & $\begin{array}{l}\text { Carteira Escolar } \\
\text { Cadeira Rodas }\end{array}$ & $\mathrm{D} / \mathrm{E}$ & $\mathrm{D} / \mathrm{E}$ \\
\hline \multirow[t]{2}{*}{ P6 } & A13 & $\mathrm{F}$ & 13 & 5 & PC & Cad. Rodas* & $\begin{array}{l}\text { Mesa redonda } \\
\text { Cadeira Rodas }\end{array}$ & $\mathrm{D} / \mathrm{E}$ & - \\
\hline & A14 & $\mathrm{F}$ & 11 & 3 & PC & Cad. Rodas* & $\begin{array}{c}\text { Outra mesa } \\
\text { Cadeira Rodas }\end{array}$ & $\mathrm{D} / \mathrm{E}$ & $\mathrm{D} / \mathrm{E}$ \\
\hline P7 & A15 & $\mathrm{M}$ & 9 & 2 & $\mathrm{PC}$ & Cad. Rodas* & $\begin{array}{l}\text { Mesa redonda } \\
\text { Cadeira Rodas }\end{array}$ & $\mathrm{D} / \mathrm{E}$ & $\mathrm{E}$ \\
\hline
\end{tabular}

Fonte: Elaboração própria.

Legenda: F: feminino, M: masculino; PC: Paralisia Cerebral, Mielo: Mielomeningocele; E: esquerdo; D: direito *Cadeira de Rodas Manual, **Deambulação independente.

Em relação à hipótese diagnóstica eram dez alunos com Paralisia Cerebral e cinco com Mielomeningocele. A encefalopatia crônica não progressiva da infância, mais conhecida como paralisia cerebral, descreve um grupo de desordens permanentes do desenvolvimento do movimento e postura atribuído a um distúrbio não progressivo que ocorre durante o desenvolvimento do cérebro fetal ou infantil, podendo contribuir para limitações no perfil de funcionalidade da pessoa. Pode ser acompanhada por distúrbios sensoriais, perceptivos, cognitivos, de comunicação e comportamentais, por epilepsia e por problemas musculoesqueléticos secundários (ROSENBAUM et al., 2007).

A mielomeningocele é definida como um sério defeito do tubo neural, acompanhada de problemas na inervação da porção inferior do tronco e dos membros inferiores; de acordo com o grau da mielodisplasia e nível de lesão, acondicionam-se diversos graus de alterações ortopédicas e neurológicas, bem como observam-se alterações urológicas (FREITAS JÚNIOR; MIRANDA, 2011).

No Quadro 3 caracteriza-se os alunos quanto à linguagem, escrita e realização de atividades acadêmicas. 
Quadro 3: Caracterização dos alunos quanto a linguagem, escrita e atividades acadêmicas.

\begin{tabular}{|c|c|c|c|c|c|c|c|c|c|}
\hline $\begin{array}{l}\text { Parti } \\
\text { cipan } \\
\text { tes }\end{array}$ & $\begin{array}{c}\text { Alu } \\
\text { no }\end{array}$ & $\begin{array}{l}\text { Gê } \\
\text { ne } \\
\text { ro }\end{array}$ & $\begin{array}{l}\text { Ida } \\
\text { de } \\
\text { (an } \\
\text { os) } \\
\end{array}$ & $\begin{array}{c}\text { Ano } \\
\text { Esco } \\
\text { lar }\end{array}$ & $\begin{array}{c}\text { Hipóte } \\
\text { se } \\
\text { Diagnós } \\
\text { tica } \\
\end{array}$ & $\begin{array}{l}\text { Lingua } \\
\text { gem } \\
\text { recepti } \\
\text { va } \\
\end{array}$ & $\begin{array}{l}\text { Lingua } \\
\text { gem } \\
\text { expres } \\
\text { siva } \\
\end{array}$ & Escrita & $\begin{array}{l}\text { Atividades } \\
\text { Acadêmicas }\end{array}$ \\
\hline P1 & A1 & $\mathrm{M}$ & 8 & 3 & Mielo & $\mathrm{V}$ & $\mathrm{V}$ & $\begin{array}{l}\text { Escrita } \\
\text { manual } \\
\end{array}$ & Sim \\
\hline \multirow[t]{3}{*}{ P2 } & A2 & M & 7 & 1 & PC & $\mathrm{V}$ & V & Computador & Sim \\
\hline & A3 & $\mathrm{F}$ & 6 & 1 & PC & $\mathrm{V}$ & $\mathrm{V}$ & $\begin{array}{l}\text { Escrita } \\
\text { manual }\end{array}$ & Sim \\
\hline & A4 & $\mathrm{M}$ & 11 & 5 & $\mathrm{PC}$ & $\mathrm{V}$ & $\mathrm{V}$ & Computador & Não \\
\hline \multirow[t]{4}{*}{ P3 } & A5 & $\mathrm{F}$ & 8 & 3 & $\mathrm{PC}$ & $\mathrm{V}$ & V & $\begin{array}{l}\text { Escrita } \\
\text { manual }\end{array}$ & Sim \\
\hline & A6 & M & 14 & 5 & PC & $\mathrm{V}$ & $\begin{array}{l}\text { Gestos/ } \\
\text { MC }\end{array}$ & Computador & Sim \\
\hline & A7 & $\mathrm{M}$ & 12 & 5 & Mielo & $\mathrm{V}$ & $\mathrm{V}$ & $\begin{array}{l}\text { Escrita } \\
\text { manual }\end{array}$ & Sim \\
\hline & A8 & $\mathrm{M}$ & 9 & 4 & Mielo & $\mathrm{V}$ & $\mathrm{V}$ & $\begin{array}{l}\text { Escrita } \\
\text { manual }\end{array}$ & Sim \\
\hline \multirow[t]{2}{*}{ P4 } & A9 & $\mathrm{M}$ & 9 & 3 & Mielo & $\mathrm{V}$ & $\mathrm{V}$ & $\begin{array}{l}\text { Escrita } \\
\text { manual }\end{array}$ & Não \\
\hline & A10 & $\mathrm{M}$ & 7 & 1 & PC & $\begin{array}{l}\text { Gestos/ } \\
\text { MC }\end{array}$ & $\begin{array}{c}\text { Gestos/ } \\
\text { MC }\end{array}$ & Computador & Não \\
\hline \multirow[t]{2}{*}{ P5 } & A11 & $\mathrm{M}$ & 7 & 2 & Mielo & $\mathrm{V}$ & $\mathrm{V}$ & Computador & Não \\
\hline & A12 & $\mathrm{M}$ & 7 & 2 & $\mathrm{PC}$ & $\mathrm{V}$ & $\mathrm{V}$ & $\begin{array}{l}\text { Letras } \\
\text { móveis }\end{array}$ & Não \\
\hline \multirow[t]{2}{*}{ P6 } & A13 & $\bar{F}$ & 13 & 5 & $\mathrm{PC}$ & $\mathrm{V}$ & $\mathrm{V}$ & Computador & Não \\
\hline & A14 & $\mathrm{F}$ & 11 & 3 & $\mathrm{PC}$ & $\mathrm{V}$ & $\mathrm{V}$ & $\begin{array}{c}\text { Não } \\
\text { escreve }\end{array}$ & Não \\
\hline P7 & A15 & M & 9 & 2 & $\mathrm{PC}$ & $\mathrm{V}$ & V & $\begin{array}{l}\text { Letras } \\
\text { móveis }\end{array}$ & Não \\
\hline
\end{tabular}

Fonte: Elaboração própria.

Legenda: F: feminino, M: masculino; PC: Paralisia Cerebral, Mielo: Mielomeningocele, V: Verbal; Gestos/MC: Gestos e movimentos do corpo. Atividades acadêmicas: Realiza atividades acadêmicas perto do nível de sua série escolar?

Os alunos que não utilizavam linguagem verbal se comunicavam por meio de gestos e movimentos do corpo, e a professora do AEE estava introduzindo o sistema de comunicação alternativa. Dos 15 alunos, seis utilizavam a escrita manual (A1, A3, A5, A7, A8 e A9), com lápis comum, jumbo ou adaptado. No entanto, A2, A4, A6, A10, A11 e A13 utilizavam o computador. Dois alunos (A12 e A15) utilizavam letras móveis sobre uma placa imantada e somente um (A14) não utilizava nenhuma forma de escrita.

Os meios de escrita mencionados no Quadro 3 são as principais formas de escrita utilizadas pelos alunos. Alguns alunos não utilizavam somente uma forma de escrita, então, foi solicitado que a professora mencionasse as três formas de escrita mais utilizadas pelo aluno. Os alunos A2, A4 e A11 utilizam o computador, mas também 
escreviam à mão, ao contrário de A5 e A9, que utilizam o computador como uma segunda opção de escrita. Os alunos A12 e A15 utilizavam letras móveis e também o computador, como segunda opção para escrever.

\section{Trabalho escrito}

A categoria trabalho escrito foi subdividida nas seguintes subcategorias: atividades básicas de escrita, atividades complexas de escrita e atividades de cópia.

\section{a) Atividades básicas de escrita}

A subcategoria Atividades básicas de escrita é composta a partir das seguintes atividades: identificar corretamente o ponto onde começar e onde parar na folha, escrever nas linhas ou no espaço designado na folha, escrever números e letras em tamanho apropriado, produzir palavras e números com qualidade aceitável, escrever da esquerda para a direita.

No Gráfico 1 observa-se o desempenho dos alunos, na realização da atividade de identificar corretamente o ponto onde começar e onde parar na folha. Oito alunos apresentaram um desempenho consistente nesta atividade, cinco apresentaram um desempenho parcial e dois não desempenharam.

Gráfico 1 - Dados referentes ao Desempenho em Atividades básicas de escrita.

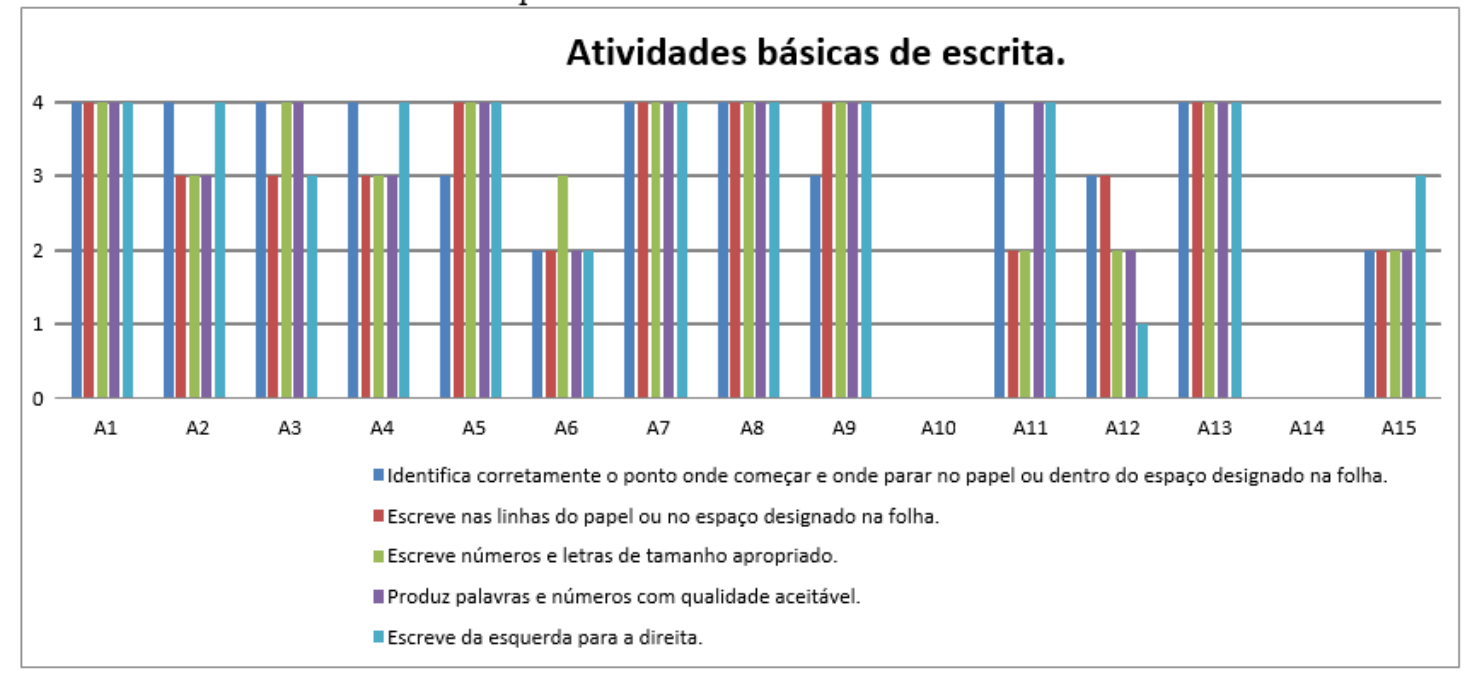

Fonte: Elaboração própria. 
Observa-se o desempenho dos alunos na realização da atividade de escrever nas linhas ou no espaço designado na folha. Seis alunos apresentaram um desempenho consistente nesta atividade, sete apresentaram um desempenho regular e dois não desempenharam. As participantes relataram que sete alunos traçavam números e letras em tamanho apropriado. Seis apresentaram um desempenho parcial e dois não conseguiram.

$\mathrm{Na}$ realização da atividade de produzir palavras e números com qualidade aceitável, dos 15 alunos, oito apresentavam um bom desempenho, cinco apresentavam um desempenho parcial e dois não conseguiram. $\mathrm{Na}$ atividade de escrever da esquerda para a direita, dos 15 alunos, nove apresentavam um desempenho consistente, três apresentavam um desempenho parcial, dois não foi possível avaliar e um não desempenhou.

\section{b) Atividades complexas de escrita}

A subcategoria atividades complexas de escrita foi composta das seguintes atividades: Observar a posição de vários itens na folha e se não omite itens, Deixar espaços apropriados entre as palavras, Alinhar números e palavras quando necessário, Organizar itens escritos em uma página e Produzir trabalho escrito com velocidade apropriada.

No Gráfico 2 observa-se o desempenho dos alunos na realização da atividade de observar a posição de vários itens na folha e não omitir itens. Nesta atividade cinco alunos obtiveram um bom desempenho, oito precisaram de ajuda e dois não conseguiram realizar.

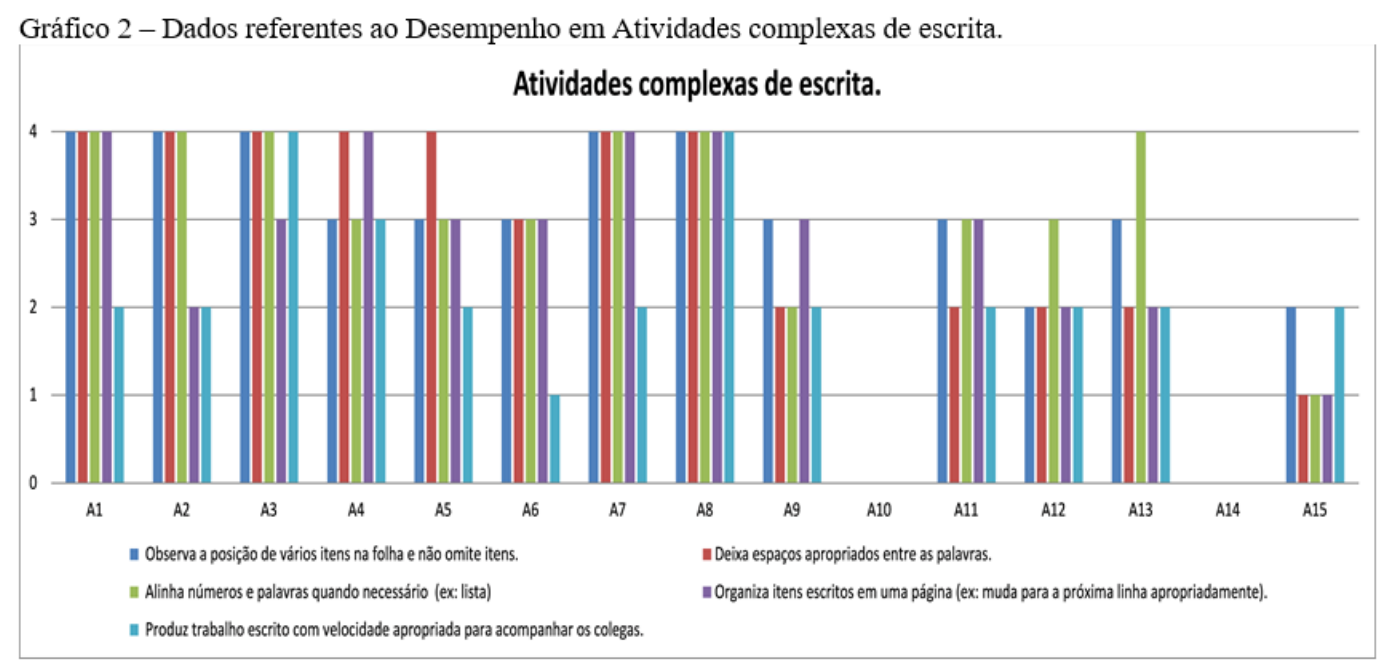

Fonte: Elaboração própria. 
Observa-se o desempenho dos alunos na realização da atividade de deixar espaços apropriados entre as palavras. Nesta tarefa sete alunos conseguiram desempenho consistente, cinco obtiveram desempenho parcial, um realizou com muita ajuda e dois não apresentaram as habilidades necessárias para iniciar a atividade.

Nota-se o desempenho dos alunos na realização da atividade de alinhar números e palavras quando necessário, como, por exemplo, na elaboração de uma lista. Nesta atividade seis alunos conseguiram desempenho consistente, seis obtiveram desempenho parcial, um realizou com muita ajuda e dois não desempenharam.

Quanto à tarefa de organizar itens escritos em uma página, como, por exemplo, na mudança de linha, inserção do título, e outros, quatro alunos realizaram plenamente a tarefa, oito necessitaram de auxílio ou adaptação, um aluno não conseguiu desempenhar e dois não realizaram atividades relacionadas à escrita. Na tarefa de produzir trabalho escrito com velocidade apropriada, somente dois alunos (A3 e A8) conseguiram plenamente, os demais apresentam lentidão para atividades de escrita e dois alunos (A10 e A14) não desempenharam.

\section{c) Atividades de cópia}

No Gráfico 3 observa-se o desempenho dos alunos na realização da tarefa de copiar material de uma fonte próxima. Nesta atividade, seis alunos conseguiram desempenho consistente, sete obtiveram desempenho parcial e dois não realizaram.

Gráfico 3 - Dados referentes ao Desempenho em Atividades de cópia.

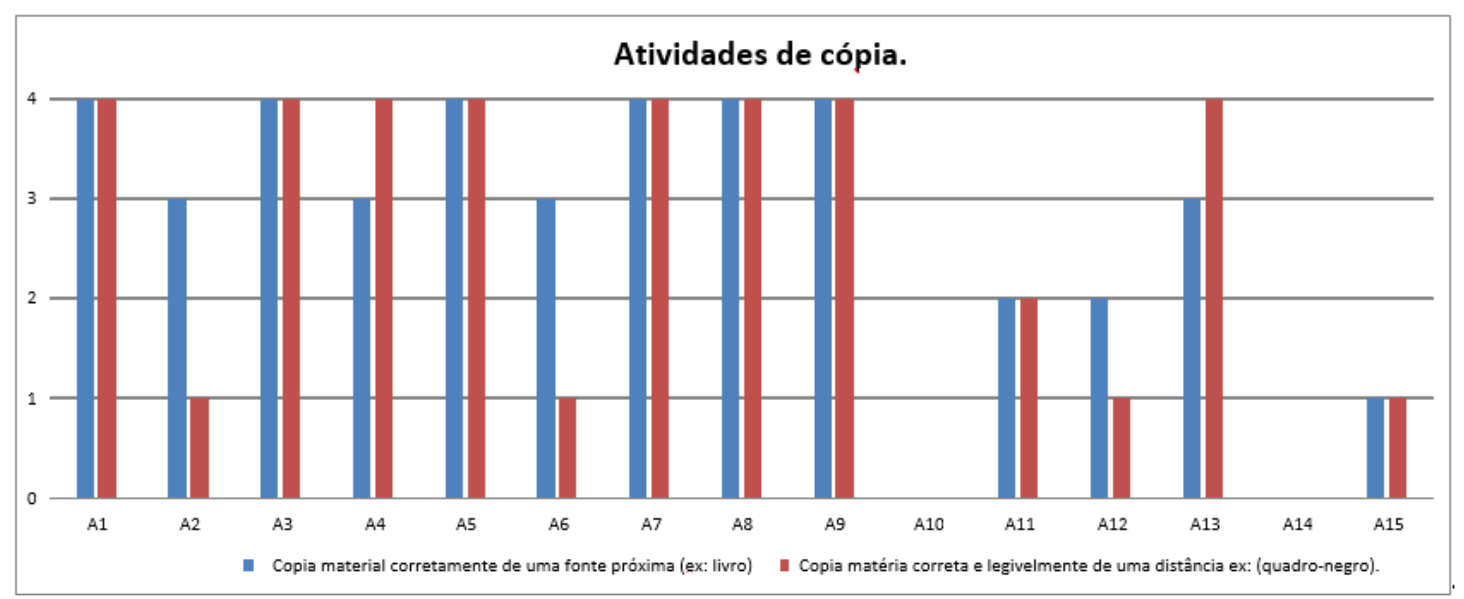

Fonte: Elaboração própria.

Quanto ao desempenho na execução de copiar material correta e legivelmente de uma distância, oito alunos conseguiram desempenho consistente, um aluno apresentou 
um pouco de dificuldade, quatro alunos muita dificuldade e dois não realizaram nenhum tipo de tarefa de escrita.

\section{Uso do computador e equipamentos}

Nesta categoria foram analisadas as tarefas de Uso do computador e equipamentos. Para detalhamento desta análise as tarefas foram redirecionadas, formando duas subcategorias: Executa as funções do computador e equipamentos, e Desenvolve atividades usando o computador.

\section{a) Executa as funções do computador e equipamentos}

Nesta subcategoria foi analisado o desempenho em tarefas de acionar o equipamento usando uma chave simples, localizar e apertar uma ou duas teclas em sequência para acionar as funções do computador, localizar e apertar três ou mais teclas em sequência para acionar as funções do computador, usar o mouse para acionar as funções do computador, inserir e retirar pen drive e $C D$ do computador.

Observa-se no Gráfico 4 que 10 alunos dominavam plenamente a tarefa de acionar o equipamento (computador) usando uma chave simples. Dois alunos (A6 e A12) conseguiam realizar com ajuda e três (A10, A14 e A15) precisavam de ajuda intensiva, denotando que o uso da TA poderia favorecer estes alunos à melhorar seu desempenho.

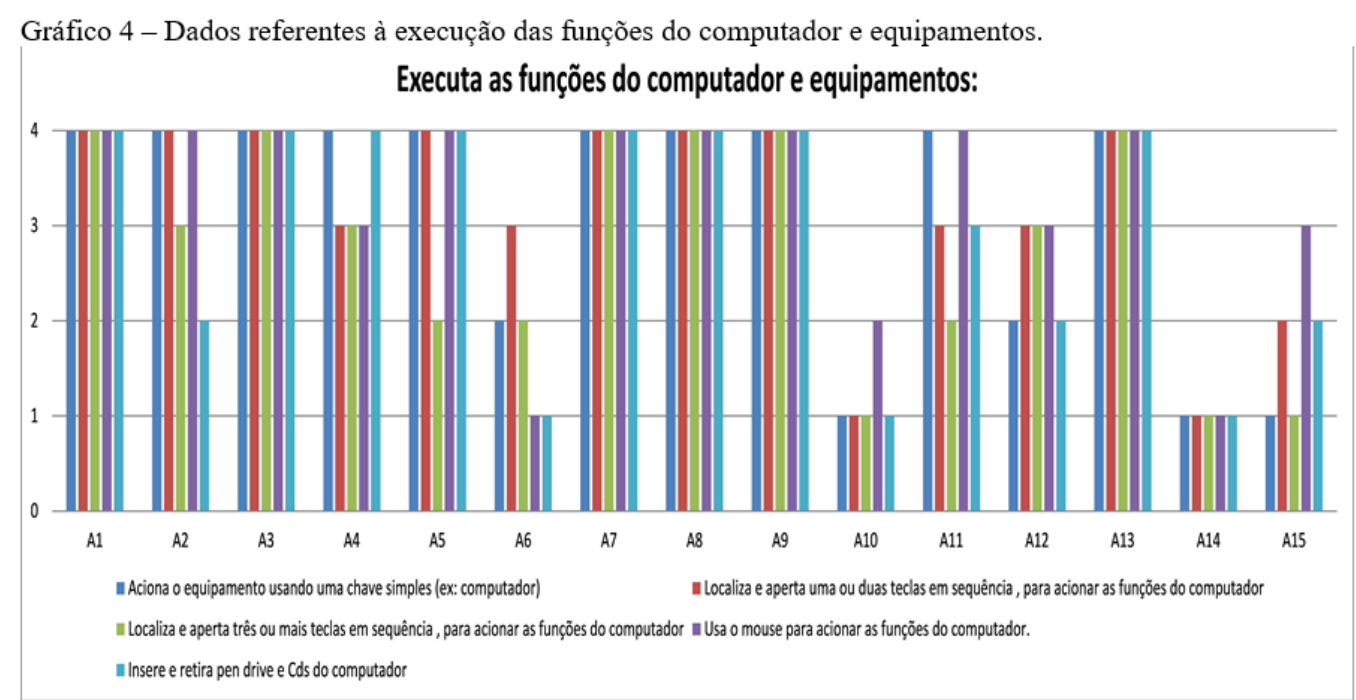

Fonte: Elaboração própria. 
Nota-se que oito dos 15 alunos dominaram a tarefa de localizar e apertar uma ou duas teclas em sequência, para acionar as funções do computador, cinco apresentaram um desempenho parcial e dois não desempenharam. Seis alunos dominaram plenamente a tarefa de localizar e apertar três ou mais teclas em sequência, para acionar as funções do computador, outros seis realizaram um desempenho parcial e três não conseguiram realizar.

Observa-se que nove alunos dominaram plenamente a tarefa de usar o mouse para acionar as funções do computador. Quatro realizaram um desempenho parcial e dois não desempenharam. Na atividade de inserir e retirar pen drive ou $\mathrm{CD}$ do computador, oito alunos tiveram um bom desempenho, quatro um desempenho parcial e três não conseguiram.

\section{b) Desenvolve atividades usando o computador}

Nesta subcategoria foi analisado o desempenho dos alunos em atividades desenvolvidas por meio do uso do computador. De acordo com o expresso no Gráfico 5, cinco alunos dominaram plenamente a tarefa de produzir uma sentença completa no computador em tempo aceitável, outros cinco realizaram um desempenho parcial e outros cinco não conseguiram.

Gráfico 5 - Dados referentes a desenvolver atividades usando o computador.

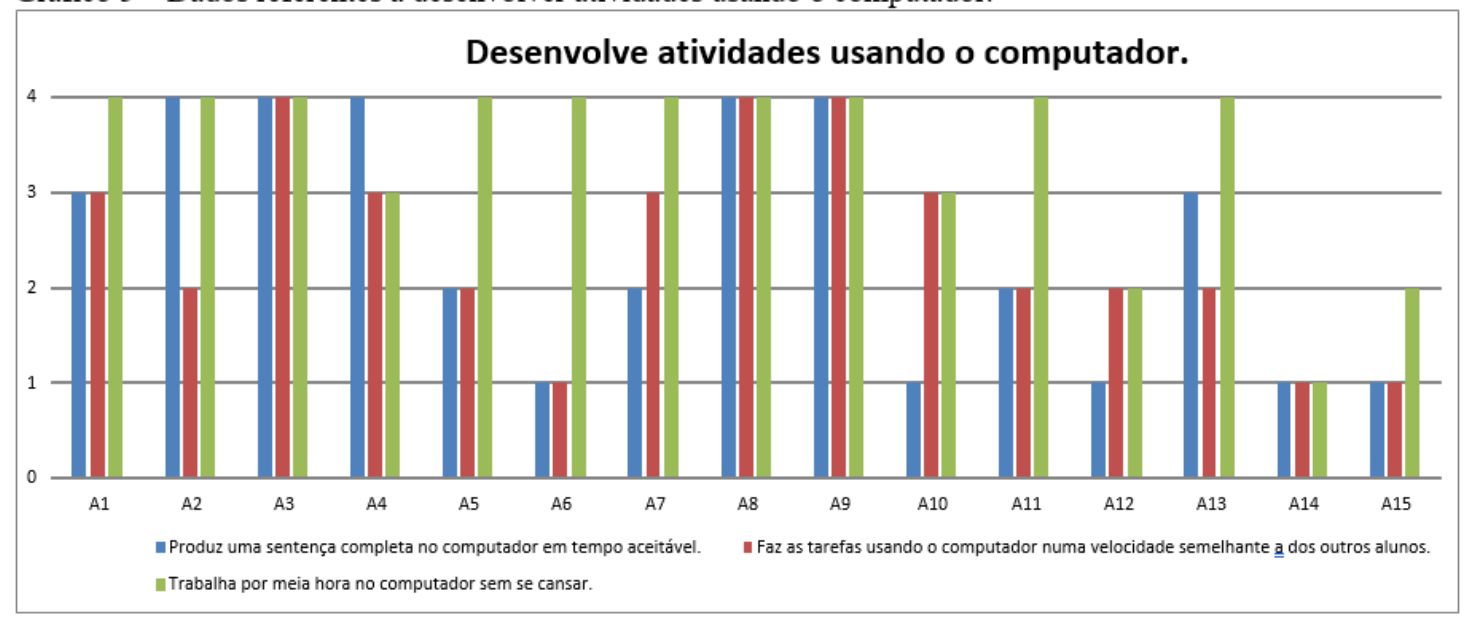

Fonte: Elaboração própria.

Nota-se que três alunos dominavam plenamente tarefas usando o computador numa velocidade semelhante a dos outros alunos, outros nove realizaram um desempenho parcial e outros três não conseguiram. Observa-se que dez alunos 
dominavam plenamente a tarefa de trabalhar por meia hora no computador sem se cansar. Porém quatro precisaram de ajuda e um não conseguia desempenhar.

\section{Discussão}

Os estudantes com deficiência física, principalmente os que apresentam a funcionalidade de membros superiores prejudicada, podem sentir dificuldades para escrever utilizando-se das maneiras convencionais (lápis e papel), mas isso não significa que eles não possam escrever. Eles necessitam dos recursos de TA, seja da alta ou baixa tecnologia, para poder desenvolver suas habilidades de escrita.

Neste contexto, o Atendimento Educacional Especializado vem contribuir para ensinar a usar a TA, visando ampliar as habilidades funcionais dos estudantes com deficiência, aumentando sua participação e incentivando a autonomia na área escolar.

Os dados relativos à forma de escrita utilizada pelos estudantes suscitam a problematização da elegibilidade para o uso do recurso, pois A11 e A13 não apresentavam comprometimento de membros superiores, no entanto utilizavam o computador como principal forma de escrita. Em relação a A13, que tem paralisia cerebral (PC), deve ser enfatizado que mesmo que ela tenha habilidades em membros superiores preservadas, ela pode apresentar dificuldade para acompanhar o ritmo e velocidade dos demais alunos da sala. Estudos indicam que os alunos com PC podem apresentar dificuldades na habilidade de escrita, na capacidade em manter a velocidade durante longos períodos de tempo, em manter a postura, e há presença de dor durante as atividades (DUBOIS et al., 2004), além de dificuldade em acompanhar as demandas exigidas na escola (CHENG et al., 2013)

Portanto, o computador, neste caso, não estava sendo usado como um recurso de TA e sim como recurso pedagógico para trabalhar as dificuldades de aprendizagem apresentadas. Estudo desenvolvido por Braccialli et al. (2016), concluiu que crianças e adolescentes com paralisia cerebral não conhecem os recursos e as opções de acessibilidade ao computador. Os autores mostraram que as pessoas com maior comprometimento, que poderiam usar o computador como TA, não têm tido essa oportunidade.

Santos e Sousa (2011) colocam que o acesso ao computador deve incluir a eliminação de barreiras arquitetônicas, equipamentos e programas adequados, além da 
apresentação de conteúdos em formatos alternativos que permitam a compreensão por pessoas com deficiência.

Estes resultados indicam que se faz necessário analisar quais recursos de TA poderiam auxiliar na melhora do uso do computador, como comenta Pedro (2012), que concluiu em sua pesquisa que para aqueles alunos que apresentavam alguma dificuldade em manusear os componentes do computador, nenhuma atividade era oferecida para tentar desenvolver essa habilidade, prejudicando sua participação. Para Galvão Filho (2012), a TA relacionada à área computacional abre novas possibilidades para as pessoas com deficiência.

De acordo com os Parâmetros Curriculares Nacionais para o ensino da Língua Portuguesa (PCN) no primeiro ciclo do ensino fundamental, é necessário "organizar situações de aprendizagem que possibilitem a discussão e reflexão sobre a escrita alfabética" (BRASIL, 2001, p. 105), e sugere-se um trabalho com gêneros discursivos, entre eles listas, bilhetes, etc. É muito importante o professor ter conhecimento do perfil funcional do aluno para respaldar seu planejamento, perceber as habilidades desenvolvidas e em qual área deve focar suas estratégias, promovendo adaptações dos recursos e assistência quando necessário.

Devido à implantação das SRM, alguns recursos e materiais passaram a estar presentes nas escolas dos municípios que aderiram ao programa federal, porém, ainda há dificuldade no uso e na execução de adaptações necessárias para atender a necessidade do aluno, como exposto por Oliveira (2016).

\section{Considerações finais}

Mostra-se importante aprimorar o levantamento do perfil funcional do aluno para escolha do recurso a ser utilizado ou adaptado, para que não ocorra de um recurso ser usado somente porque está presente, sem ganhos acadêmicos ou funcionais para o aluno. Neste sentido, seria importante que fosse incluído no kit que o MEC fornece às escolas para composição das SRM, materiais, equipamentos e mobiliários que permitissem ao professor do AEE, em parceria com uma equipe interdisciplinar de apoio, uma adequada avaliação da participação e desempenho dos alunos com DF, com enfoque nas potencialidades do aluno. 
Neste kit, além dos recursos atualmente existentes, que também fosse oferecido recursos de TA mais específicos às necessidades do estudante com DF, como: separadores de folhas, engrossadores de lápis, mouse estático de esfera, mesa com recorte em semicírculo, cadeira adaptada que possa ser ajustada de acordo com o perfil do aluno, caderno de madeira, letras de madeira imantadas, placa imantada, letras de madeira com velcro, placa com tiras de velcro, miniaturas para comunicação alternativa, software que disponha de sistema de varredura, teclado com teclas ampliadas, quadro interativo, notebook com tela touch e tablets com softwares e aplicativos específicos, dentre outros materiais, que facilitariam o ensino de atividades de escrita no AEE.

Agradecimentos: Financiamento CAPES.

\section{REFERÊNCIAS}

ABE, P. B. Desempenho funcional nas atividades de rotina escolar de alunos com necessidades educacionais especiais na perspectiva do professor. 100f. Dissertação (Mestrado em Educação) - Faculdade de Filosofia e Ciências, Universidade Estadual Paulista Júlio de Mesquita Filho, Marília, 2009.

BAGAGI, P. S. Habilidades funcionais de alunos com deficiência matriculados no ensino infantil: avaliação de professores. Marília, 98f. Dissertação (Mestrado em Educação) - Faculdade de Filosofia e Ciências, Universidade Estadual Paulista, 2010.

BRACCIALLI, L. M. P. Tecnologia Assistiva: perspectiva de qualidade de vida para pessoas com deficiência. In: VILARTA, R. et al. (Org.). Qualidade de vida e novas tecnologias. Campinas, Ipes editorial, p. 105- 113, 2007.

BRASIL. Parâmetros Curriculares Nacionais: Língua Portuguesa. Ministério da Educação. Secretaria de Educação Fundamental. 3 ed. Brasília. MEC/SEF, 2001.

BRACCIALLI, L. M. P.; SPILLER, M. G.; AUDI, M.; ARAÚJO, A. L.; SANKAKO, A. N. Acesso ao computador por crianças e jovens com paralisia cerebral.

Educação, Formação \& Tecnologias, v. 9, n. 1, p. 72-84, 2016.

COSTER, W. J. et al. School Function Assessment. San Antonio, TX: Harcourt brace \& Company; Therapy Skill Builders, 1998.

COSTER, W. et al. School participation, supports and barriers of students with and without disabilities. Child: care, health and development, vol. 39, p. 535-543, 2013.

CHENG, H.-Y. K.; LIEN, Y.-J.; YU, Y.-C.; et al. The effect of lower body stabilization and different writing tools on writing biomechanics in children with cerebral palsy. 
Research in developmental disabilities, v. 34, p. 1152-1159, 2013. Disponível em: <http://dl.acm.org/citation.cfm?id=2500753.2500799>. Acesso em: 10 ago. 2017.

DUBOIS, L.; KLEMM, A.; MURCHLAND, S.; OZOLS, A. Handwriting of children who have hemiplegia: A profile of abilities in children aged 8-13 years from a parent and teacher survey. Australian Occupational Therapy Journal, v. 51, n. 2, p. 89-98, 2004.

FREITAS JÚNIOR, S.; MIRANDA, M. L. A importância da investigação e seguimento urológicos. In: SPERS, V. R. E.; PENACHIM, E. A. S; GARBELLINI, D. (Orgs.) Mielomeningocele: o dia a dia, a visão dos especialistas e o que esperar do futuro. Piracicaba, Unigráfica, 2011.

GALVÃO FILHO, T. A. Tecnologia Assistiva: favorecendo o desenvolvimento e a aprendizagem em contextos educacionais inclusivos. In: GIROTO, C. R. M.; POKER, R.B.; OMOTE, S. (org.) As tecnologias nas práticas pedagógicas inclusivas. Marília, Oficina Universitária; São Paulo, Cultura Acadêmica, p. 65-92, 2012.

OLIVEIRA, C. C. B. Sala de recursos multifuncionais: um estudo de caso. 2016. 168f. Dissertação (Mestrado em Educação). Universidade Estadual Paulista, Faculdade de Filosofia e Ciências, Marília, 2016.

ORGANIZAÇÃO MUNDIAL DE SAÚDE. CIF: Classificação internacional de funcionalidade, incapacidade e saúde. Lisboa, 2004.

PEDRO, K. M. Softwares educativos para alunos com deficiência intelectual: planejamento e utilização. 98f. Dissertação (Mestrado em Educação) - Universidade Estadual Paulista "Júlio de Mesquita Filho", Faculdade de Filosofia e Ciências, Marília, 2012.

QUEIROZ, F. M. M. G.; BRACCIALLI, L. M. P. Perfil Funcional das crianças com deficiência física acompanhadas pelo atendimento educacional especializado em uma escola do interior paulista. Anais... V Congresso internacional de Saúde da criança e do adolescente. V CISCA. Journal of human growth and development, p. 130, 2013.

RÉZIO, G. S. Independência funcional, motricidade e participação escolar e suas relações no desenvolvimento da criança com paralisia cerebral. $2012.139 \mathrm{f}$. Dissertação (Mestrado) - Pró-Reitoria de Pós-Graduação e Pesquisa, Pontifícia Universidade Católica de Goiás, Goiânia, 2012.

ROSENBAUM, P. et al. A report: the definition and classification of cerebral palsy. Developmental Medicine and Child Neurology, v. 49, n.1, p. 8-14, 2007.

SANTOS, L. P.; SOUSA, P, R. Novas tecnologias e pessoas com deficiências: a informática na construção da sociedade inclusiva? In: SOUSA, P, R.; MOITA, F.M.C.S.C., CARVALHO, A.B.G. (Orgs.) Tecnologias digitais na educação. Campina Grande: EDUEPB, 2011.

STAINBACK, S.; STAINBACK, W. Inclusão: um guia para educadores; trad. Magda França Lopes, Porto Alegre, Artes Médicas Sul, 1999. 
VYGOTSKY, L. S. Fundamentos da defectologia. Madrid: Visor, Obras Escogidas, v. 5. 1997.

VYGOTSKY, L. S. A formação social da mente: O desenvolvimento dos processos Psicológicos Superiores, São Paulo, Martins Fontes, 2003.

\section{Como referenciar este artigo}

QUEIROZ, Fernanda Matrigani Mercado Gutierres de.; BRACCIALLI, Lígia Maria Presumido. Funcionalidade de alunos com deficiência física nas atividades de escrita e de uso do computador. Revista Ibero-Americana de Estudos em Educação, Araraquara, v. 12, n. esp. 2, p. 1267-1286, ago./2017. Disponível em: <http://dx.doi.org/10.21723/riaee.v12.n.esp.2.10295>. E-ISSN: 1982-5587.

Submetido em: 30/04/2017

Aprovação final em: 28/06/2017 